\title{
Distal pancreatectomy for spontaneous rupture of the splenic artery
}

\author{
J. M. PORTER \\ F.R.C.S.
}

\author{
O. M. FEnTON \\ F.R.C.S.
}

St Alban's City Hospital, Normandy Road, St Albans, Herts.

\begin{abstract}
Summary
Two patients with haemoperitoneum due to spontaneous haemorrhage near the tail of the pancreas are described. One patient presented acutely with epigastric pain and was found to be bleeding from the main trunk of the splenic artery. The other presented with a prolonged history of epigastric pain culminating in a haematemesis and was found to have a partially organized haematoma in the tail of the pancreas. In both cases the bleeding was proximal to the splenic pedicle, and distal pancreatectomy with splenectomy was necessary to achieve haemostasis.
\end{abstract}

\section{Introduction}

Spontaneous rupture of an intra-abdominal artery in the absence of trauma or aneurysm is a rare but well described cause of haemoperitoneum (Gough and Strong, 1978; Stevenson, Mansfield and Temple, 1978). In an analysis of 129 consecutive cases of haemoperitoneum, only 3 were ascribed to spontaneous intraperitoneal haemorrhage (Ellis, Griffiths and MacIntyre, 1958). The initial haemorrhage is often localized by haematoma, producing nonspecific signs and failure to proceed to laparotomy until subsequent intraperitoneal haemorrhage has occurred. Spontaneous bleeding from the splenic artery has been recorded on 8 occasions (Smith, 1911; MacLeod and Maurice, 1940; Tanna, 1946; Gillam, 1948; Gallagher and Hudson, 1954; WardMcQuaid, 1961; Hanna and Myles, 1964). Seven cases were operated on with one death. In each case haemostasis was achieved by splenectomy, dividing the splenic vessels proximal to the bleeding point.

\section{Case reports}

\section{Case 1}

A previously healthy man, aged 69 years, was referred with a 16-hr history of epigastric pain. The pain was of sudden onset and was initially severe, radiating to both shoulders. He fainted, revived after a few moments and was left with a dull epigastric ache, made worse by lying flat.

On examination he was pallid and sweating. The BP was $100 / 80 \mathrm{mmHg}$ and the pulse rate was
$100 / \mathrm{min}$. The epigastrium was tender without rigidity, bowel sounds were present and rectal examination was normal. $\mathrm{Hb}$ was $11.6 \mathrm{~g} / \mathrm{dl}$ and WBC $14.4 \times 10^{9} / 1$. The blood pressure fell to $90 / 60 \mathrm{mmHg}$, the abdomen developed generalized tenderness with rigidity and laparotomy was therefore undertaken after transfusion.

Two litres of dark blood were found in the peritoneum and rapid arterial bleeding was seen near the splenic pedicle. Access to the bleeding was difficult because the patient was deep-chested. The spleen and distal pancreas were rapidly mobilized with division of the short gastric vessels, and the source of bleeding was located $5 \mathrm{~cm}$ proximal to the splenic pedicle. It was decided that a secure suture ligation would devascularize the spleen and the pancreatic tail, therefore the pancreas was divided proximal to the bleeding point, the pancreatic duct was ligated and a tube drain was placed near the pancreatic stump. The patient recovered uneventfully.

Pathology. The splenic artery was atheromatous but perforation had occurred in an otherwise healthy segment of artery.

\section{Case 2}

An 83-year-old man was referred with a onemonth history of left hypochondrial pain, productive cough and weight-loss. He had been taking prednisolone $5 \mathrm{mg}$ daily for 2 years for aplastic anaemia of unknown aetiology. On examination he was clinically anaemic and dehydrated. The liver was palpable but the abdomen was otherwise normal. $\mathrm{Hb}$ was $7.5 \mathrm{~g} / \mathrm{dl}$. The chest X-ray showed bilateral basal opacities and the sputum was positive for squamous cell carcinoma. He was transfused and discharged on a course of ampicillin.

Two months later he was re-admitted, having passed melaena stools for 3 days. His abdominal pain had persisted and the $\mathrm{Hb}$ was $6.4 \mathrm{~g} / \mathrm{dl}$. He was again transfused and discharged. Seventeen days later he was re-admitted with an 8-hr history of severe epigastric pain. He vomited $150 \mathrm{ml}$ of fresh blood on admission. The epigastrium was tender 
with rigidity and rectal examination disclosed fresh melaena stool. $\mathrm{Hb}$ was $8.4 \mathrm{~g} / \mathrm{dl}$.

Laparotomy disclosed $1500 \mathrm{ml}$ of dark blood in the peritoneum. A mass was found in the tail of the pancreas, adherent to the posterior wall of the stomach and gastrotomy revealed a minute ulcer at the point of adherence. The mass was found to be the source of intraperitoneal bleeding. The splenic artery was ligated in continuity, proximal and distal to the mass and the bleeding point was under-run. The spleen was not removed because of the aplastic anaemia, to conserve haemopoietic tissue. The lesser sac was drained.

Forty-eight hr later, rapid blood loss commenced through the drain. Re-exploration showed a steady ooze of blood from the pancreatic tail. The spleen was intact. The pancreatic tail was too friable to hold a secure suture, therefore haemostasis was achieved by distal pancreatectomy with splenectomy. Initially the patient made good progress but he died of a chest infection and renal failure 21 days after surgery.

Pathology. The mass in the pancreatic tail was found to be an organizing haematoma. The splenic artery was occluded by atheroma as far as the splenic hilum and the haematoma did not connect with the splenic artery or vein. Post-mortem showed bronchopneumonia with no evidence of lung cancer, renal tubular necrosis and a gastropancreatic fistula.

The initial pathology was thought to be the rupture of a small artery in the pancreatic tail with haematoma formation, adherence to the stomach, intermittent intra-gastric bleeding and final rupture into the peritoneum.

\section{Discussion}

Rupture of a non-aneurysmal splenic artery has been reported once at post-mortem and 7 times at operation. Seven patients were previously healthy young adults. Out of 6 females, 4 were pregnant and one was post partum. The duration of symptoms varied from 2 weeks to $3 \mathrm{hr}$ and 4 patients had nonspecific abdominal signs before collapsing. In 7 patients a terminal branch of the splenic artery had ruptured in the splenic hilum; 6 of these were submitted to splenectomy with one death. In one patient the main artery had ruptured $2.5 \mathrm{~cm}$ proximal to the splenic hilum; this case was successfully treated by splenectomy and ligation of the ruptured artery. No operative specimen showed atherosclerosis. There was one post-operative death; a hypertensive male of 52 years died in circulatory collapse $14 \mathrm{hr}$ after surgery.

The 2 cases reported contrast with the 8 reviewed. Both were elderly men and both bled near the pancreatic tail. Atherosclerosis was present in both operative specimens, although not at the point of rupture. In case 1 the clinical and operative findings were otherwise similar to those previously reported? The clinical features of case 2 were unprecedented. Ellis, Griffiths and MacIntyre (1958) described $\overrightarrow{\bar{\phi}}$ similar pathology: at post-mortem a male of 52 yeares was found to have bled from a small artery in the head of the pancreas.

The diagnosis of spontaneous intra-abdomina bleeding is nearly always made at laparotomy. The history may be helpful if non-specific abdomina symptoms precede the onset of shock and peritonism $\vec{D}$ but the patient's condition usually precludes sophisticated investigation. Visceral angiograph\& has been suggested if difficulty is encountered locating the bleeding point (Gough and Strong\% 1978). If the patient is pregnant in the second of third trimester and if the history is suggestiven rupture of the splenic artery is strongly indicated.

Haemorrhage from the splenic artery poses particular operative problems. Ligation in situ is clearly the simplest treatment; however, the bleeding point may be difficult to visualize and there is the risk of injury to the spleen or pancreas. The splenio artery has numerous small branches, one of which may continue to bleed after proximal and dista ligation. Division of the lieno-renal ligament and, is necessary, the short gastric vessels, enables $\overrightarrow{\mathrm{b}} \overrightarrow{\mathrm{e}}$ spleen and distal pancreas to be mobilized rapidi thus delivering the site of bleeding from within abdomen. Ligature of the splenic artery proximarte the short gastric vessels should not devascularize tho spleen (Gallagher and Hudson, 1954); however, the rapid mobilization is likely to cause further bleeding from the splenic hilum or capsule. Splenectomy the safest course of action.

Operation upon the pancreas carries the risk of pancreatic fistula and should be avoided if possible If the short gastric vessels have been divided, if the pancreatic tail is distal to the ruptured vessel and a secure suture ligation encloses pancreatic tissues. then the pancreatic tail will probably be devasculas ized and should be removed.

If the pancreatic tail is the site of long-standing bleeding it will be oedematous and friable, stitches will cut out, and the whole pathological process should be removed by distal pancreatectomy.

\section{Acknowledgments}

We thank Mr P. Stringer and Mr J.C.F. Townsend för permission to publish cases under their care, Dr Ivor Pugd for examining the pathology specimens, and Mrs A. Portê for typing the manuscript.

\section{References}

Ellis, H., Griffiths, P.W.W. \& MacIntyre, A. (195\& Haemoperitoneum. A record of 129 consecutive patients with notes on some unusual cases. British Journal of Surgery, 45, 606. 
Gallagher, H.W. \& Hudson, K. (1954) Rupture of the splenic artery complicating pregnancy. British Medical Journal, 2, 1209.

GillaM, J.F.E. (1948) Spontaneous rupture of the splenic artery. British Journal of Surgery, 36, 203.

Gough, I.R. \& Strong, R.W. (1978) Abdominal apoplexy. British Journal of Surgery, 65, 318.

Hanna, W.A. \& Myles, T.J.M. (1964) Spontaneous intraperitoneal haemorrhage during pregnancy: report of three cases. British Medical Journal, 1, 1024.
MacLeod, D.H. \& Maurice, T. (1940) Rupture of a branch of the splenic artery. Lancet, $\mathbf{i}, 924$.

SmITH, H.S.W. (1911) A fatal case of intraperitoneal haemorrhage from an unusual source. British Medical Journal, 1, 83.

Stevenson, I.M., Mansfield, A.O. \& Temple, J.G. (1978) Abdominal apoplexy. British Journal of Surgery, 65, 318.

TANNA, J.F. (1946) Abdominal apoplexy. American Journal of Surgery, 73, 132.

WARD-MCQUAID, J.N. (1961) Splenic aneurysms. British Journal of Surgery, 48, 646. 